\title{
Median Baseline Removal Method
}

National Cancer Institute

\section{Source}

National Cancer Institute. Median Baseline Removal Method. NCI Thesaurus. Code C64240.

Method for identifying invariant set normalization baseline using median expression values. Defined in the documents available at http://bioconductor.org/packages/1.9/bioc/html/affy.html. 